\title{
The Amino Terminus of the Coat Protein of Turnip crinkle virus Is the AVR Factor Recognized by Resistant Arabidopsis
}

\author{
Yajuan Zhao, ${ }^{1}$ Leanna DelGrosso,, ${ }^{1}$ Erbay Yigit, ${ }^{1}$ D'Maris Amick Dempsey, ${ }^{2}$ Daniel F. Klessig, ${ }^{2}$ \\ and Kristin K. Wobbe ${ }^{1}$ \\ ${ }^{1}$ Worcester Polytechnic Institute, Department of Chemistry and Biochemistry, 100 Institute Rd., Worcester, \\ MA 01609, U.S.A.; ${ }^{2}$ Waksman Institute and Department of Molecular Biology and Biochemistry, Rutgers, \\ the State University of New Jersey, 190 Frelinghuysen Rd., Piscataway, NJ 08854-8020, U.S.A. \\ Accepted 1 June 2000.
}

We have isolated three naturally occurring strains of Turnip crinkle virus (TCV) that break resistance in $\mathrm{Di}-17$ Arabidopsis. Two mutations in the $\mathrm{N}$ terminus of the TCV coat protein, D4N and P5S, were shown to confer this phenotype. Thus, this region of the coat protein is involved in eliciting resistance responses in Arabidopsis.

Plants have developed resistance responses to limit the growth and spread of many attacking pathogens. One form of resistance is controlled by a gene-for-gene relationship that postulates a direct or indirect interaction between the product(s) of the plant resistance $(R)$ gene and a pathogen produced avirulence (avr) molecule. This interaction results in pathogen recognition and initiation of plant resistance responses (Flor 1947, 1971). A common visible characteristic of gene-for-gene mediated resistance is the hypersensitive response (HR), in which necrotic lesions form at the sites of infection on the inoculated leaves. Usually the pathogen is restricted to these lesions. Also associated with the resistance response is the induction of a number of defenseassociated genes, including the pathogenesis-related $(P R)$ genes.

A variety of plant $R$ genes that confer resistance to different microbial and insect pathogens have been cloned (for review see Baker et al. 1997; Jones and Jones 1997; Ellis and Jones 1998). In some cases, their cognate $a v r$ molecules also have been identified. For viral pathogens, the coat protein (CP; Culver and Dawson 1991; de la Cruz et al. 1997; BerzalHerranz et al. 1995; Bendahmane et al. 1995), the replicase (Padgett and Beachy 1993; Padgett et al. 1997; Kim and Palukaitis 1997; Erickson et al. 1999), and the movement protein(s) (Weber and Pfitzner 1998) all have been shown to serve as $a v r$ factors in different plant/viral systems. However, little is understood about the mechanisms through which these viral $a v r$ proteins work with the cognate plant $R$ gene products to activate resistance responses.

Corresponding author: K. K. Wobbe; Telephone: 1-(508) 831-5375; Fax: 1-(508) 831-5933; E-mail: kwobbe@wpi.edu
To provide further insights into viral resistance mechanisms, we are studying the interaction between Turnip crinkle virus (TCV) and Arabidopsis. The TCV genome consists of a 4,054 nucleotide RNA that encodes two proteins involved in replication (p28, p88), two required for movement (p8, p9), and the CP (Carrington et al. 1989). Two distinct, though similar, strains of TCV, TCV-M and TCV-B, were shown to be virulent on most ecotypes of Arabidopsis. However, one ecotype, Dijon, was found to be partially resistant ( $\mathrm{Li}$ and $\mathrm{Si}$ mon 1990; Simon et al. 1992). From this ecotype we isolated a completely TCV-susceptible line, designated Di-3, that becomes systemically infected and dies within 2 to 3 weeks of inoculation. A TCV-resistant line, termed Di-17, also was isolated; these plants develop a visible HR by 3 days post inoculation (dpi; Dempsey et al. 1993). The ability of Di-17 plants to respond hypersensitively to TCV requires a single dominant gene, designated HRT ( $\underline{\mathrm{HR}}$ to $\underline{\mathrm{TCV}}$ infection; Dempsey et al. 1997), which was recently cloned (Cooley et al. 2000).

While most TCV-inoculated Di-17 plants develop no symptoms beyond the HR, a small subset of these plants occasionally display systemic disease symptoms. To determine whether the TCV-M viral stock contained a population of naturally occurring mutant viruses capable of systemically infecting Di-17 plants, total RNA was extracted from the uninoculated portions of seven Di-17 plants displaying systemic symptoms. Each RNA was then used to inoculate about 20 Di-17 plants. One of these seven RNA samples produced systemic symptoms on $100 \%$ of the inoculated plants, despite the appearance of an HR by 3 dpi. RNA was extracted from the uninoculated portions of one of these plants and used to inoculate another set of Di-17 plants. Again, $100 \%$ of the inoculated plants developed systemic symptoms following the appearance of few to no lesions. The RNA isolated from the uninoculated portions of one of these plants was then inoculated on a third round of $\mathrm{Di}-17$ plants. None of these plants exhibited an HR following infection and all developed systemic symptoms. Strikingly, the progression of disease symptoms in these plants mimicked that observed in susceptible plants inoculated with TCV-M. Based on these results, a mu- 

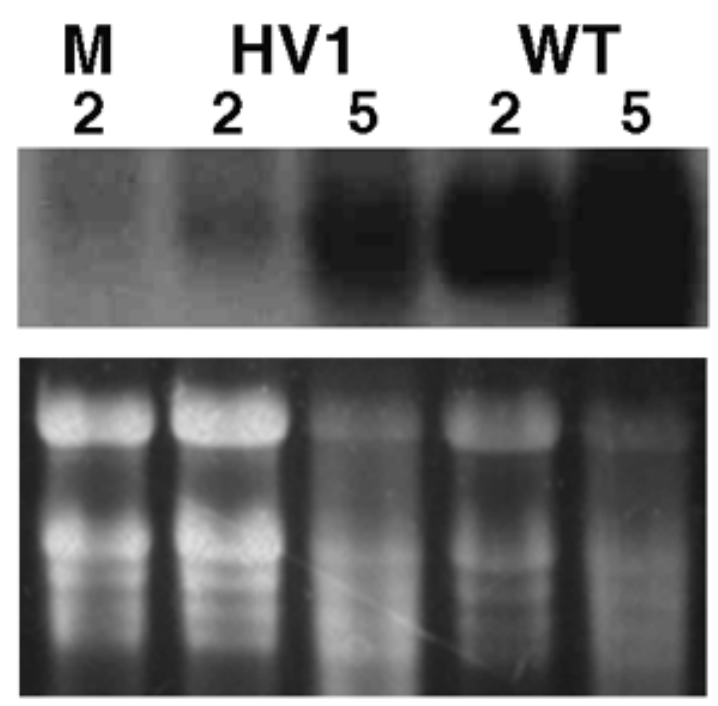

Fig. 1. $P R-1$ expression in mock- and virus-inoculated Di-17 leaves. Di17 plants were inoculated with either TCV-HV1 (HV1), TCV-M (WT), or inoculation buffer (M) (Dempsey et al. 1993). RNA gel blot analysis was performed according to Dempsey et al. (1993) with RNA extracted from virus-inoculated leaves at 2 and 5 days post inoculation (dpi), and mock-inoculated leaves at 2 dpi. Five micrograms of RNA was loaded in each lane and the blots were hybridized with a $P R-1 \mathrm{cDNA}$. As a control for loading levels, the ethidium bromide-stained gel is shown below. tant virus, tentatively named TCV-HV1, appears to be present in the TCV-M viral stock. Moreover, the lack of a visible HR suggests that Di-17 plants fail to recognize TCV-HV1 and therefore do not activate the appropriate defenses.

It was previously demonstrated that $P R-1$ gene expression is induced more rapidly and to significantly greater levels in TCV-inoculated Di-17 plants than in susceptible plants (Dempsey et al. 1993). To determine if this resistanceassociated response is activated in Di-17 plants inoculated with TCV-HV1, we monitored $P R-1$ expression in the inoculated leaves of plants infected with TCV-HV1 or wild-type TCV-M at 2 and 5 dpi. Northern (RNA) analysis revealed that $P R-1$ expression was rapidly induced to high levels after inoculation with TCV-M (Fig. 1). In contrast, significantly lower levels of $P R-1$ transcripts were detected in plants inoculated with TCV-HV1 at both timepoints.

To determine the molecular basis for the resistance breaking phenotype, the bulk of the 4-kb TCV-HV1 genomic RNA was cloned with reverse transcription-polymerase chain reaction (RT-PCR). The $5^{\prime}$ half, extending from an SphI site (nucleotide 445; Fig. 2A) to a BamHI site (nucleotide 2,360), and the $3^{\prime}$ half, extending from a BamHI site (nucleotide 2,361 ) to an SpeI site (nucleotide 3,950), were independently amplified and cloned into pBluescript-SK+ (Stratagene, La Jolla, CA). Interestingly, while several attempts were made to amplify the very $3^{\prime}$ end of the TCV-HV1 genome (nucleotides

A

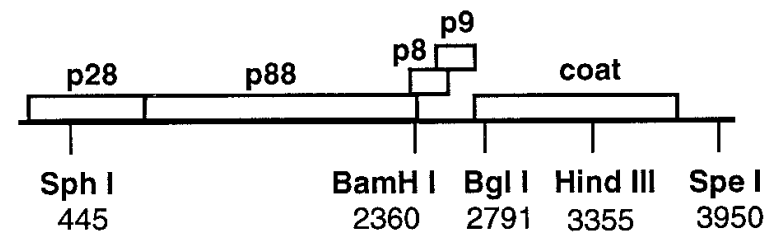

B

TCV-B
TCV-HV1 (Sphl-BamH I)
TCV-HV1 (BamH I-Hind III)
TCV-HV1 (Hind III-Spe I)
TCV-HV1 (BamH I-BgI I)
TCV-HV1 (BgI I-Hind III)
TCV-D4N
TCV-P5S

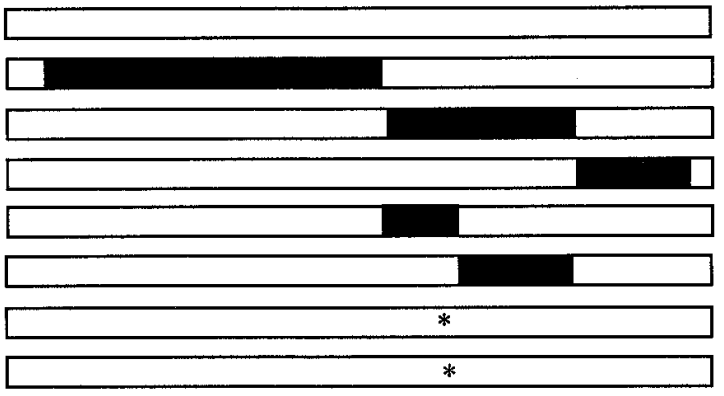

$\begin{array}{r}\% \text { Systemic } \\
\text { Disease }\end{array}$
\begin{tabular}{rr|c|l} 
Di-3 & Di-17 & Lesions & Symptom \\
\hline 100 & 30 & Yes & mild, late \\
100 & 0 & Yes & NA \\
100 & 100 & No & mild, early \\
100 & 0 & Yes & NA \\
100 & 90 & No & mild, early \\
67 & 0 & Yes & NA \\
100 & 100 & No & mild, early \\
100 & 100 & No & mild, early
\end{tabular}

Fig. 2. Diagram of the genome of Turnip crinkle virus (TCV), the chimeric constructs, and their effects on Arabidopsis. A, Representation of the TCV genome. Open reading frames are represented by boxes above the thick line and labeled according to the encoded protein. Restriction sites used to create the chimeric TCV-HV1 constructs are indicated below the line, with the nucleotide number of the cleavage site underneath. B, Chimeric genomes are diagrammed according to their TCV-B (open box) and TCV-HV1 (black box) content. Asterisks (*) denote sites of single base mutations. Site-directed mutagenesis was done according to McPherson et al. (1991). pT1d1 1 l (Heaton et al. 1989; M. Akgoz, K. Drainville, A. Talmadge, and K. K. Wobbe, unpublished) was used as a template. Mutagenic primers were D4NR (5'-CTAGGATTATTTTCC-3'), D4NL (5'-GCATCAACACTGGAATGG-3'), P5SR (5'-GGAAAATGATTCCAGAGTCCGGAAG-3'), P5SL (5'-CGGACTCTGGAATCATTTTCCATTTCC-3'). Outside primers were SpeI (5'-GCACTA GTTTTCCAGTCTAATG-3'), mid 5 (5'-GTGATAGATGGATCCTG-3'). Resulting mutagenic DNA fragments, digested with BamHI and HindIII, were used to replace the corresponding segment of pT1d1Al. "Lesions" and "Symptom severity" refer to results of inoculation on Di-17 plants only. Early symptoms are visible at 6 to 10 days post inoculation (dpi). Late symptoms are visible more than 14 dpi. Chimeras were tested by inoculating plants with normalized amounts of in vitro transcribed RNA from indicated constructs. Results reported for D4N and P5S were from plants inoculated with RNAs harvested from turnips inoculated with in vitro transcribed RNA. NA = not applicable. All experiments were conducted at least three times with similar results. 
3,951 to 4,054 ) with a primer complementary to the TCV $3^{\prime}$ end (GCTCTAGAGGGCAGGCCCCCCCCC), none were successful, though in each case amplification of either TCV-M or TCV-B was obtained. The cloned TCV-HV1 genome was then sequenced (Table 1). Comparison of this sequence with those reported for TCV-M and TCV-B revealed that the TCVHV1 genome differs at many sites from both TCV-B and TCV-M, resulting in amino acid differences in each of the virally encoded proteins.

The region of the TCV-HV1 genome responsible for the resistance breaking phenotype was then identified by producing chimeric viruses containing fragments of RT-PCRgenerated TCV-HV1 sequences inserted into the TCV-B clone, pT $1 \mathrm{~d} 1 \Delta \mathrm{l}$ (Heaton et al. 1989). Initially three chimeras were produced: TCV-HV1 (SphI/BamHI); TCV-HV1 (BamHI/HindIII); and TCV-HV1 (HindIII/SpeI) (Fig. 2B). Each of these chimeras was transcribed in vitro and the resulting RNAs were inoculated on susceptible Di-3 and resistant Di-17 Arabidopsis plants as in Wobbe et al. (1998). All susceptible Di-3 plants displayed systemic disease symptoms within a week of inoculation, demonstrating that the transcripts were infectious. Di-17 plants inoculated with TCV-HV1 (SphI/BamHI) and TCV-HV1 (HindIII/SpeI) did not develop systemic disease; instead, these plants developed an HR on the inoculated leaves and remained healthy through 20 dpi. However, all Di-17 plants inoculated with TCV-HV1 (BamHI/HindIII) RNA displayed systemic symptoms after $10 \mathrm{dpi}$ and no lesions were observed. Therefore, this portion (BamHI/HindIII) of TCV-HV1 appears to carry the resistance breaking mutation.

Table 1. Sequence differences between TCV-M, TCV-B, and TCV-HV1 for regions that have been sequenced in TCV-HV1

\begin{tabular}{|c|c|c|c|}
\hline Nucleotide number & $\mathbf{M}^{\mathbf{a}}$ & $\mathbf{B}^{\mathbf{b}}$ & HV1 \\
\hline 593 & $\mathrm{C}$ & $\mathrm{T}$ & $\mathrm{T}$ \\
\hline 1143 & $\mathrm{G}$ & $\mathrm{A}$ & $\mathrm{G}$ \\
\hline $1214-5$ & $\mathrm{AC}$ & CA & CA \\
\hline 1328 & $\mathrm{C}$ & $\mathrm{T}$ & $\mathrm{T}$ \\
\hline 1467 & $A(K)^{c}$ & $\mathrm{~A}(\mathrm{~K})$ & $\mathrm{G}(\mathrm{E})$ \\
\hline 1622 & A & $\mathrm{G}$ & A \\
\hline 1664 & $\mathrm{~T}(\mathrm{D})$ & $\mathrm{T}(\mathrm{D})$ & $\mathrm{A}(\mathrm{E})$ \\
\hline 1803 & $\mathrm{~T}$ & $\mathrm{~T}$ & $\mathrm{C}$ \\
\hline 1958 & $\mathrm{~T}$ & $\mathrm{C}$ & $\mathrm{C}$ \\
\hline 1973 & $\mathrm{~T}$ & $\mathrm{C}$ & $\mathrm{C}$ \\
\hline 1997 & A & A & G \\
\hline 2351 & $\mathrm{~T}$ & $\mathrm{~T}$ & $\mathrm{C}$ \\
\hline 2429 & $\mathrm{~A}(\mathrm{~K})$ & $\mathrm{G}(\mathrm{E})$ & $\mathrm{G}(\mathrm{E})$ \\
\hline 2476 & $\mathrm{~T}$ & $\mathrm{~T}$ & G \\
\hline 2511 & $\mathrm{G}(\mathrm{S} / \mathrm{V})^{\mathrm{d}}$ & $\mathrm{G}(\mathrm{S} / \mathrm{V})$ & $\mathrm{A}(\mathrm{N} / \mathrm{I})$ \\
\hline 2752 & $\mathrm{G}(\mathrm{D})$ & $\mathrm{G}(\mathrm{D})$ & $\mathrm{A}(\mathrm{N})$ \\
\hline 2913 & A & G & A \\
\hline 2950 & $\mathrm{~A}(\mathrm{~T})$ & $\mathrm{T}(\mathrm{S})$ & $\mathrm{T}(\mathrm{S})$ \\
\hline 3013 & $\mathrm{~A}(\mathrm{~T})$ & $\mathrm{A}(\mathrm{T})$ & $\mathrm{G}(\mathrm{A})$ \\
\hline 3096 & $\mathrm{G}$ & $\mathrm{G}$ & A \\
\hline 3113 & $\mathrm{~T}(\mathrm{~V})$ & $\mathrm{C}(\mathrm{A})$ & $\mathrm{C}(\mathrm{A})$ \\
\hline 3207 & $\mathrm{~T}$ & $\mathrm{C}$ & $\mathrm{T}$ \\
\hline 3216 & $\mathrm{C}$ & A & $\mathrm{T}$ \\
\hline 3863 & A & A & $-^{\mathrm{e}}$ \\
\hline
\end{tabular}

a Sequence from Oh et al. (1995).

b Sequence from Carrington et al. (1989) with corrections from Collmer et al. (1992).

${ }^{c}$ Letters in parentheses represent amino acid changes.

${ }^{d}$ This nucleotide encodes two over-lapping proteins. The first listed is the amino acid encoded in $\mathrm{p} 8$, the second is the amino acid in $\mathrm{p} 9$.

${ }^{\mathrm{e}}$ Represents a 1-base deletion.
To further delineate the region conferring the resistance breaking phenotype, two additional chimeric clones were constructed (Fig. 2B). Di-17 plants infected with TCV-HV1 (BglI/HindIII) developed lesions and did not display systemic symptoms as late as 20 dpi. Di-17 plants inoculated with TCVHV1 (BamHI/BglI), however, failed to develop lesions and displayed systemic disease symptoms by $10 \mathrm{dpi}$. Thus, the region conferring the hypervirulent phenotype resides within a 431-bp $B a m \mathrm{HI} / B g l$ I fragment that encodes the eight $\mathrm{C}$-terminal amino acids of the p88 replicase, all but the initiating methionine of $\mathrm{p} 8$, all of $\mathrm{p} 9$, and $16 \mathrm{~N}$-terminal amino acids of the CP.

The sequence of the TCV-HV1 BamHI/BglI fragment revealed four differences from the TCV-M and TCV-B genomic sequences. Two of these mutations (nucleotides 2,449 and 2,476 ) are silent at the protein level, one (nucleotide 2611) results in simultaneous changes in p8 (Ser to Asn) and p9 (Val to Ile), and one (nucleotide 2,752) causes a change in amino acid 4 of the CP (Asp to Asn) (Table 1). Site-directed mutagenesis (McPherson et al. 1991) was used to produce the single base change $(\mathrm{G} \rightarrow \mathrm{A})$ in the $\mathrm{CP}$ of the wild-type TCV$\mathrm{B}$ clone. RNA transcribed from the new mutant, D4N, was inoculated on both Di-3 and Di-17 plants. No lesions formed on either Di-3 or Di-17 plants and all developed systemic symptoms (Fig. 2B). Sequence analysis of the BamHI to BglI region of a cDNA clone produced from RNA extracted from systemically infected Di-17 plants showed no changes other than the single directed mutation. Therefore, the D4N mutation at nucleotide 2,752 is sufficient to confer hypervirulence.

Two additional resistance breaking mutants, TCV-HV2 and TCV-HV3, were independently isolated with the same serial passaging strategy employed to isolate TCV-HV1. The 431nucleotide Bam $\mathrm{HI}$ to $B g l \mathrm{I}$ region of both mutants was cloned and sequenced. This region of TCV-HV2 was shown to contain the same D4N mutation as TCV-HV1. The equivalent region of TCV-HV3 is identical to TCV-B except for a $\mathrm{C}$ to $\mathrm{T}$ transition at nucleotide 2,755; this results in a proline to serine change at amino acid 5 (P5S) of the CP. The P5S mutation was subsequently produced by site-directed mutagenesis in the wild-type TCV-B clone and analyzed for its effect on virulence. Di-17 plants inoculated with this mutant also did not produce lesions and developed systemic disease symptoms with kinetics similar to those observed with D4N (Fig. 2B).

Several studies have indicated that the presence of the TCV $\mathrm{CP}$ is critical for viral recognition and induction of resistance responses (Oh et al. 1995; Kong et al. 1995, 1997; Wang and Simon 1999; Cooley et al. 2000). We therefore tested whether the D4N or P5S mutations led to reduced CP accumulation in the resistance breaking mutants. Western blot (immunoblot) analysis of proteins extracted from symptomatic, infected Di-3 plants showed that the level of CP produced by the TCV-HV1, D4N, and P5S mutants was not substantially different from that of the wild-type TCV-M (data not shown). Thus, the hypervirulent phenotype associated with the D4N and P5S mutations appears to be due solely to amino acid identity changes at these positions. Consistent with this conclusion, the addition of two amino acids to the $\mathrm{N}$ terminus of the TCV CP was recently shown to produce a virus that expressed wild-type levels of CP but caused systemic disease symptoms in Di-0 plants (Wang and Simon 1999).

It is currently unclear how mutations in the $\mathrm{N}$ terminus of the TCV CP lead to the resistance breaking phenotype. This 
region of the $\mathrm{CP}$ is thought to reside within the virion (Hogle et al. 1986). Thus, recognition of TCV infection by the host plant is not likely to occur until either the virus is uncoated or CP synthesis begins. Resistance in many other plant/pathogen systems is similarly triggered subsequent to the initial presence of the virion (Culver et al. 1994; Taraporewala and Culver 1996; Bendahmane et al. 1995; Padgett and Beachy 1993; Padgett et al. 1997; Kim and Palukaitis 1997; Erickson et al. 1999; Weber and Pfitzner 1998). For the host plant, the ability to recognize external domains on a given pathogen may be selected against because resistance breaking mutations could be readily accomplished without altering a vital viral function. By contrast, recognition of protein domains involved in other functions carries the potential benefit that many mutations resulting in non-recognition would also have a deleterious effect on viral function. Thus, there appears to be a strong selective advantage for the plant to develop recognition of a functional region of the pathogen.

\section{ACKNOWLEDGMENTS}

We would like to thank T. Jack Morris for the gift of the TCV coat protein antibody and the pT1d1 clone, and Anne Simon for the parental TCV-M virus stock, the TCV-ms clone, and sequence. We would like to acknowledge the technical assistance of Jennifer Wright and Steven Tyler. We would also like to thank Jacek Hennig for his intellectual contributions and Muslum Akgoz, Thomas Hammond, and Frederic Souret for critical reading of the manuscript. This research was funded in part by USDA grants (97-35311-5137) to K. K. W. and (97-35303-4520) to D. F. K.

\section{LITERATURE CITED}

Baker, B., Zambryski, P., Staskawicz, B., and Dinesh-Kumar, S. P. 1997. Signaling in plant-microbe interactions. Science 276:726-733.

Bendahmane, A., Kohn, B. A., Dedi, C., and Baulcombe, D. C. 1995. The coat protein of potato virus $\mathrm{X}$ is a strain-specific elicitor of $R \times 1$ mediated virus resistance in potato. Plant J. 8:933-941.

Berzal-Herranz, A., de la Cruz, A., Tenllado, F., Díaz-Ruíz, J. R., López, L., Sanz, A. I., Vaquero, C., Serra, M. T., and García-Luque, I. 1995. The Capsicum L3 gene-mediated resistance against the tobamovirus is elicited by the coat protein. Virology 209:498-505.

Carrington, J. C., Heaton, L. A., Zuidema, D., Hillman, B. I., and Morris, T. J. 1989. The genome structure of turnip crinkle virus. Virology 170:219-225.

Collmer, C. W., Stenzler, L., Chen, X., Fay, N., Hacker, D., and Howell, S. H. 1992. Single amino acid change in the helicase domain of the putative RNA replicase of turnip crinkle virus alters symptom intensification by virulent satellites. Proc. Natl. Acad. Sci. USA 89:309-313.

Cooley, M. B., Pathirana, S., Wu, H.-J., Kachroo, P., and Klessig, D. F. 2000. Members of the Arabidopsis HRT/RPP8 family of resistance genes confer resistance to both viral and oomycete pathogens. Plant Cell 12:663-676.

Culver, J. N., and Dawson, W. O. 1991. Tobacco mosaic virus elicitor coat protein genes produce a hypersensitive phenotype in transgenic Nicotiana sylvestris plants. Mol. Plant-Microbe Interact. 4:458-463.

Culver, J. N., Stubbs, G., and Dawson, W. O. 1994. Structure-function relationship between tobacco mosaic virus coat protein and hypersensitivity in Nicotiana sylvestris. J. Mol. Biol. 242:130-138.

de la Cruz, A., López, L., Tenllado, F., Díaz-Ruíz, J. R., Sanz, A. I., Vaquero, C., Serra, M. T., and García-Luque, I. 1997. The coat protein is required for the elicitation of the Capsicum $\mathrm{L}^{2}$ gene-mediated resistance against the tobamoviruses. Mol. Plant-Microbe Interact. 10:107-113.

Dempsey, D. A., Pathirana, M. S., Wobbe, K. K., and Klessig, D. F. 1997. Identification of an Arabidopsis locus required for resistance to turnip crinkle virus. Plant J. 11:301-311.

Dempsey, D. A., Wobbe, K. K., and Klessig, D. F. 1993. Resistance and susceptible response of Arabidopsis thaliana to turnip crinkle virus. Mol. Plant Pathol. 83:1021-1029.

Ellis, J., and Jones, D. 1998. Structure and function of proteins controlling strain-specific pathogen resistance in plants. Curr. Opin. Plant Biol. 1:288-293.

Erickson, F. L., Holzberg, S., Calderon-Urrea, A., Handley, V., Axtell, M., Corr, C., and Baker, B. 1999. The helicase domain of the TMV replicase proteins induces the $\mathrm{N}$-mediated defense response in tobacco. Plant J. 18:67-75.

Flor, H. 1947. Inheritance of reaction to rust in flax. J. Agric. Res. $74: 241-262$.

Flor, H. 1971. Current status of the gene-for-gene concept. Annu. Rev. Phytopathol. 9:275-296.

Heaton, L. A., Carrington, J. C., and Morris, T. J. 1989. Turnip crinkle virus infection from RNA synthesized in vitro. Virology 170:214-218.

Hogle, J. M., Maede, A., and Harrison, S. C. 1986. Structure and assembly of turnip crinkle virus. I. X-ray crystallographic structure analysis at 3.2 A resolution. J. Mol. Biol. 191:625-638.

Jones, D. A., and Jones, J. D. G. 1997. The role of leucine-rich repeat proteins in plant defenses. Adv. Bot. Res. 24:89-167.

Kim, C.-H., and Palukaitis, P. 1997. The plant defense response to cucumber mosaic virus in cowpea is elicited by the viral polymerase gene and affects virus accumulation in single cells. EMBO J. 16: 4060-4068.

Kong, Q., Oh, J.-W., Carpenter, C. D., and Simon, A. E. 1997. The coat protein of turnip crinkle virus is involved in subviral RNA-mediated symptom modulation and accumulation. Virology 238:478-485.

Kong, Q., Oh, J.-W., and Simon, A. E. 1995. Symptom attenuation by a normally virulent satellite RNA of turnip crinkle virus is associated with the coat protein open reading frame. Plant Cell 7:1625-1634

Li, X. H., and Simon, A. E. 1990. Symptom intensification on cruciferous hosts by the virulent satellite RNA of turnip crinkle virus. Phytopathology 80:238-242.

McPherson, M. J., Quireke, P., and Taylor, G. R., eds. 1991. PCR: A Practical Approach. Oxford University Press, Oxford.

Oh, J.-W., Kong, Q., Song, C., Carpenter, C. D., and Simon, A. E. 1995. Open reading frames of turnip crinkle virus involved in satellite symptom expression and incompatibility with Arabidopsis thaliana ecotype Dijon. Mol. Plant-Microbe Interact. 8:979-987.

Padgett, H. S., and Beachy, R. N. 1993. Analysis of a tobacco mosaic virus strain capable of overcoming $\mathrm{N}$ gene mediated resistance. Plant Cell 5:577-586.

Padgett, H. S., Watanabe, Y., and Beachy, R. N. 1997. Identification of the TMV replicase sequence that activates the $N$ gene-mediated hypersensitive response. Mol. Plant-Microbe Interact. 10:709-715.

Simon, A. E., Li, X. H., Lew, J. E., Stange, R., Zhang, C., Polacco, M., and Carpenter, C. D. 1992. Susceptibility and resistance of Arabidopsis thaliana to turnip crinkle virus. Mol. Plant-Microbe Interact. 5: 496-503.

Taraporewala, Z. F., and Culver, J. N. 1996. Identification of an elicitor active site within the three-dimensional structure of the tobacco mosaic tobamovirus coat protein. Plant Cell 8:169-178.

Wang, J., and Simon, A. E. 1999. Symptom attenuation by a satellite RNA in vivo is dependent on reduced levels of virus coat protein. Virology 259:234-245.

Weber, H., and Pfitzner, A. J. P. 1998. Tm-22 resistance in tomato requires recognition of the carboxy terminus of the movement protein of tomato mosaic virus. Mol. Plant-Microbe Interact. 11:498-503.

Wobbe, K. K., Akgoz, M., Dempsey, D. A., and Klessig, D. F. 1998. A single amino acid change in turnip crinkle virus movement protein $\mathrm{p} 8$ affects RNA binding and virulence on Arabidopsis thaliana. J. Virol. 72:6247-6250. 